\title{
Contextos de Abstinência e de Recaída na Recuperação da Dependência Química
}

\author{
Simone Demore Rigotto e \\ William B. Gomes ${ }^{2}$ \\ Universidade Federal do Rio Grande do Sul
}

\begin{abstract}
RESUMO - Foram entrevistados nove homens e três mulheres, residentes na região da cidade de Caxias do Sul - RS, todos diagnosticados como dependentes de substâncias, segundo critérios do DSM-IV, para que descrevessem suas experiências de abstinência e recaída nas tentativas de recuperação da dependência química. A análise qualitativa das entrevistas orientou-se pelos movimentos reflexivos de descrição, redução e interpretação fenomenológica. A experiência da abstinência foi atribuída aos seguintes constituintes e contextos experienciais: consciência do problema aditivo por parte do dependente, resgate de vínculos familiares, recomposição de auto-estima, afastamento de ambientes favorecedores da adição, e envolvimento em práticas religiosas. A ausência dos constituintes e contextos identificados na experiência de abstinência caracterizou a manutenção do consumo. Os elos experienciais interpretados como essenciais à experiência de abstinência foram as redes interpessoais de apoio - constituídas por profissionais, familiares e novos amigos - e o envolvimento como colaboradores na recuperação de outros dependentes químicos.
\end{abstract}

Palavras Chaves: drogas; dependência; abstinência; recaída; e fenomenologia existencial.

\section{Contexts of Abstinence and Setback in the Recovery of Chemical Dependence}

\begin{abstract}
Nine men and three women from Caxias do Sul region, Rio Grande do Sul State-Brazil, all diagnosed as dependents of substances according to the DSM-IV criteria, were asked to describe their experiences of abstinence and setback in the recuperation of chemical dependence. The reflexive phenomenological movements of description, reduction and interpretation guided the interviews' qualitative analysis. The abstinence experience was attributed to the following constituent and experiential context: conscience of the addictive problem by the dependents themselves, familiar bond regain, self-esteem reconstitution, turning away to the addict favouring environment, and involvement in religious practice. The absence of the constituent and context identified on the abstinence experience characterized the consumption maintenance. The experiential links interpreted as essentials to the abstinence experience were the interpersonal support nets - formed by professionals, families and new friends - and the involvement as contributors to the others chemical dependents recovery.
\end{abstract}

Key Words: drugs; dependency; abstinence; setback; and existential phenomenology.

O objetivo deste estudo é oferecer uma compreensão fenomenológica da experiência de ser um dependente químico à procura de reabilitação. Procura-se identificar, nesta experiência e na significação a ela atribuída, os elos que auxiliam o comprometimento na recuperação (reabilitação) e, em contrapartida, aqueles que retroalimentam a recaída. Por compreensão fenomenológica entende-se o movimento reversivo da percepção e expressão na constituição do sentido para todo e qualquer ato humano (Lanigan, 1997). Nesta perspectiva, o termo compreensão fenomenológica referese à condição comunicativa humana de constituir e oferecer sentido. O uso de droga, enquanto tal, é um ato comunicativo. Tal redução não implica no afastamento de outras pers-

1 Trabalho baseado na Dissertação de Mestrado com o mesmo título realizado pela primeira autora em um Programa de Mestrado Interinstitucional entre o Curso de Pós-Graduação em Psicologia da UFRGS e a Universidade de Caxias do Sul.

2 Endereço: Instituto de Psicologia - UFRGS; Rua Ramiro Barcelos, 2600/119; 90540.131 Porto Alegre - RS

E-mail: gomesw@vortex.ufrgs.br pectivas e abordagens para o problema (Leite \& Gomes, 1998) mas requer o reconhecimento da ambigüidade na constituição de sentidos. O sentido é uma escolha, consciente ou não, que surge da decodificação da experiência, isto é, na relação entre percepção e expressão. O consumo de drogas é uma forma de expressão e percepção de si mesmo, numa relação que inclui os outros e o ambiente em que se vive.

Padrões de consumo de drogas podem ser modificados por intervenções desenvolvimentais e ambientais, e por mudanças intencionais, como ocorre na psicoterapia (Prochaska $\&$ DiClemente, 1986). No entanto, tratamentos de drogadição enfrentam várias limitações tais como heterogeneidade dos dependentes, diversidade das substâncias consumidas, custos econômicos, dificuldades com recursos humanos, e dificuldades de materiais especializados. Os fatores críticos na abstinência das adições não estão relacionados à maturação, ao tratamento ou mesmo ao ajustamento pessoal mas, sim, à severidade da adição e ao tipo de experiência curativa disponível ao adicto (Vaillant, 1997). Estas posições não parecem ser unânimes na literatura. Há estudos que apontam para a baixa relação entre nível de dependência e prognóstico 
(Grant \& Harford, 1990; Schuckit, Zisook \& Mortola, 1985) e para a falta de consenso entre estimativas fornecidas por pacientes e seus terapeutas sobre o nível de dependência e possibilidade de recuperação (Pechansky, Soibelman \& Jacques, 1994). Assim, o problema parece não estar necessariamente no agravamento da dependência mas nas simplicações contextuais (Andreatini, Galduróz \& Formigoni, 1994).

A mobilidade pessoal para a obtenção da abstinência foi descrita em quatro estágios, denominados de pré-contemplação, contemplação, decisão/ação e manutenção (Prochaska \& DiClemente 1986). Na pré-contemplação o adicto pode mostrar interesse em mudar o comportamento ou ainda não parecer suficientemente consciente de que tem problemas. Na contemplação o adicto demonstra consciência do seu problema e começa a pensar em fazer mudanças, mas sem um sério compromisso para agir. Na decisão/ação, ocorrem tentativas concretas de modificar comportamentos, experiências, e meio ambiente. Por fim, na manutenção trabalhase para evitar a recaída e consolidar os ganhos.

Três condições parecem estar relacionadas à mobilidade pessoal para a remissão estável do consumo (Leite \& Gomes, 1998; Vaillant, 1997). A primeira refere-se ao abuso, por pouco tempo, de drogas muito leves e que a simples mudança nas circunstâncias de vida do adicto podem levar à remissão completa. A segunda refere-se ao abuso de drogas muito severas, o que fatalmente levará o adicto ao "fundo do poço" e à tomada de decisão de que é preciso fazer alguma coisa a favor de si mesmo. A terceira refere-se a ocorrência fortuita, na vida do adicto, de experiências que possam romper com os hábitos enraizados. As condições de remissão enunciadas incluíram os seguintes aspectos: 1) adoção de comportamentos substitutos que venham competir com a adição; 2) disponibilidade para supervisão compulsória, 3) engajamento em projetos significativos e 4) recuperação de autoestima. Os quatros aspectos apontados foram encontrados na experiência de abstinência em adictos de heroína (Maddox \& Desmond, 1981). Dos adictos de heroína estavelmente abstinentes $43 \%$ usaram como substituto o álcool ou a metadona, $42 \%$ tiveram um ano de supervisão compulsória, $17 \%$ estavam colaborando no tratamento de outros adictos em instituições, e 25\% envolveram-se em atividades religiosas. Resultados semelhantes foram encontrados em cerca de 50\% dos adictos abstinentes de heroína e álcool, em outro estudo que incluiu seguimento de longo prazo em 100 adictos de heroína e 100 dependentes de álcool (Vaillant, 1988). Enfim, a recuperação parece estar associada à definição de novos objetivos pessoais (Edwards, 1997; Waisberg \& Porter, 1994), reconhecimento de recursos pessoais que podem ser mobilizados para a manutenção da abstinência (Gossop, 1997), e percepção de autoeficácia diante de situações de risco para recaída (Marlatt, 1993).

A análise de recaídas ao longo do tempo mostrou que a estabilização da taxa de ocorrência começa a acontecer aproximadamente 90 dias após o início da abstinência (Hunt, Barnett \& Branch, 1971). No entanto, os 12 primeiros me- ses são considerados como período de alto risco de acordo com o DSM-IV (American Psychiatric Association, 1994). A clássica análise (Cummings, Gordon \& Marlatt, 1980) de 311 episódios de recaída em dependentes de álcool, tabaco, heroína, alimentos e jogo compulsivo, identificou três situações primárias associadas ao problema: 1) estados emocionais negativos (35\% das recaídas); 2) conflito interpessoal recente (16\% das recaídas) e 3) pressão social (20\% das recaídas). Estudos subseqüentes não apontaram mudanças no quadro apresentado, mas variaram quanto à definição de pontos críticos. Um estudo (Gossop, Green, Phillips \& Bradley, 1989) sobre recaídas em 80 dependentes de álcool e heroína, submetidos a tratamento em regime de internação, informou que: 1) quase dois terços daqueles que recaíram reconheceram falhas em tomadas de decisão e em planejamento de atividades (fatores cognitivos); e 2) mais da metade indicou que algum estado de humor negativo precedeu a recaída. O estudo salientou ainda que, freqüentemente, estes fatores ocorriam juntos.

A breve revisão da literatura sustenta a afirmação de especialistas de que, na compreensão da dependência química, as prevalecem as dúvidas sobre as certezas e as divergências se sobrepõem aos consensos (Sanchez-Craig, Neumann, Formigoni \& Rieck, 1991; Schuckit, Zisook \& Mortola, 1985). Em contraste, há consenso sobre o aumento acelerado do consumo em decorrência do narcotráfico e da demanda por produtos psicotrópicos (Bucher, 1996). As drogas constituem, hoje, o fator mais importante de desorganização social, familiar e individual, além dos níveis insuportáveis já alcançados pelo seu elevado custo sócio-econômico e sanitário. Sabe-se que o início do uso de drogas está ocorrendo com pessoas cada vez mais jovens e com substâncias de teor tóxico cada vez mais elevado (Bucher, 1996). Diante da complexidade do problema é prudente evitar uma posição reducionista - seja ela biológica, social ou psicológica. Devese sim estudar a dependência química através de abordagens que ultrapassem as opiniões e ideologias favorecendo a compreensões abrangentes e integradas (Bertozzi, 1993).

$\mathrm{O}$ presente estudo focaliza os constituintes autoelucidativos de depoimentos sobre a experiência de abstinência e recaída, em relação aos seus respectivos contextos. Por contexto, entende-se as condições ambientais ou espaços psicológicos onde vivem esses indivíduos. Tais condições fornecem os elementos ou constituintes que qualificam a experiência e, por conseguinte, as escolhas. Estes contextos e seus constituintes estão presentes em experiências que caracterizam a trajetória do abuso de drogas, isto é, aproximação inicial (o que levou ao consumo), envolvimento (como o uso foi se tornando habitual), dependência (quando e como foi percebida), motivações para tratamento (o que levou a procurar), e manutenção ou não da abstinência (fatores identificados como associados a uma ou outra experiência). Assim, o estudo não está interessado em formas específicas de tratamento mas na delimitação de experiências e de significações atribuídas como curativas ou como situações de risco, por dependentes químicos à procura de reabilitação. 


\section{Método}

\section{Informantes}

Participaram desta pesquisa nove homens e três mulheres, da região de Caxias do Sul, Estado do Rio Grande do Sul (Tabela 1). Todos eram dependentes de substâncias conforme diagnóstico em acordo com o DSM-IV. As principais drogas utilizadas foram álcool, maconha, cocaína e medicamentos. A via de administração era, preferencialmente, oral e inalada. Quatro participantes usaram drogas injetáveis (Tabela 2). Os informantes foram selecionados em três instituições para tratamento de dependentes de drogas, as quais utilizavam variadas abordagens terapêuticas: aconselhamento psicológico, grupos de auto-ajuda, prevenção de recaídas, comunidades terapêuticas, metodologia do amor exigente e o referencial dos 12 passos dos Alcóolicos Anônimos. Ressalte-se, contudo, que os informantes costumavam transitar entre instituições, principalmente depois de recaídas. Sete informantes tiveram problemas com o sistema judicial, envolvendo porte de armas, porte de drogas, brigas, estelionato, e furto de veículos. Todos os informantes, à época da pesquisa, mantinham o contato com a família. Apenas três indicaram a não ocorrência de dependência química em pessoas da família. Metade do grupo era independente economicamente. Os demais recorriam ao auxilio de pessoas próximas.

Os informantes foram divididos em dois grupos, cada um com seis representantes, sendo um grupo constituído por indivíduos que obtiveram sucesso na manutenção da abstinência e outro constituído por casos de recaída. Para o pro-

Tabela 1. Descrição dos participantes da pesquisa

\begin{tabular}{|c|c|c|c|c|c|}
\hline Part. & Idade & $\begin{array}{c}\text { Estado } \\
\text { civil }\end{array}$ & $\begin{array}{l}\text { Nível de } \\
\text { Instrução }\end{array}$ & Profissão & $\begin{array}{c}\text { Independência } \\
\text { Econômica }\end{array}$ \\
\hline AM1 & 31 & casado & $\begin{array}{l}2^{\circ} \text { grau } \\
\text { incompleto }\end{array}$ & $\begin{array}{l}\text { Monitor de } \\
\text { Fazenda }\end{array}$ & Sim \\
\hline RM2 & 31 & casado & $\begin{array}{l}2^{\circ} \text { grau } \\
\text { incompleto }\end{array}$ & Eletricista & Não \\
\hline RM3 & 34 & separado & $\begin{array}{l}2^{\circ} \text { grau } \\
\text { incompleto }\end{array}$ & $\begin{array}{l}\text { Auxiliar de } \\
\text { Almoxarifado }\end{array}$ & Não \\
\hline AM4 & 27 & casado & $\begin{array}{l}2^{\circ} \text { grau } \\
\text { incompleto }\end{array}$ & Eletricista & Sim \\
\hline AM5 & 24 & solteiro & $\begin{array}{l}2^{\circ} \text { grau } \\
\text { incompleto }\end{array}$ & $\begin{array}{l}\text { Monitor de } \\
\text { Fazenda }\end{array}$ & Sim \\
\hline AM6 & 19 & solteiro & $\begin{array}{l}1^{\circ} \text { grau } \\
\text { incompleto }\end{array}$ & $\begin{array}{l}\text { Monitor de } \\
\text { Fazenda }\end{array}$ & Sim \\
\hline RM7 & 21 & solteiro & $\begin{array}{l}1^{\circ} \text { grau } \\
\text { incompleto }\end{array}$ & $\begin{array}{l}\text { Auxiliar } \\
\text { Geral }\end{array}$ & Não \\
\hline AM8 & 36 & separado & $\begin{array}{l}1^{\circ} \text { grau } \\
\text { incompleto }\end{array}$ & $\begin{array}{l}\text { Operador de } \\
\text { Máquinas }\end{array}$ & Sim \\
\hline RF9 & 19 & solteira & $\begin{array}{l}1^{\mathrm{o}} \text { grau } \\
\text { completo }\end{array}$ & $\begin{array}{l}\text { Auxiliar de } \\
\text { Produção }\end{array}$ & Sim \\
\hline RF10 & 19 & solteira & $\begin{array}{l}\text { Superior } \\
\text { incompleto }\end{array}$ & Recepcionista & Não \\
\hline AF11 & 37 & separada & $\begin{array}{l}1^{\mathrm{o}} \text { grau } \\
\text { completo }\end{array}$ & Artesã & Não \\
\hline RM12 & 16 & solteiro & $\begin{array}{l}1^{\circ} \text { grau } \\
\text { incompleto }\end{array}$ & - & Não \\
\hline
\end{tabular}

Tabela 2. Idades entre início e uso regular de drogas, drogas utilizadas e tempo de abstinência atual

\begin{tabular}{|c|c|c|c|c|}
\hline Part. & $\begin{array}{c}\text { Idades do } \\
\text { início ao } \\
\text { uso regular } \\
\text { de drogas }\end{array}$ & $\begin{array}{l}\text { Drogas } \\
\text { utilizadas }\end{array}$ & $\begin{array}{c}\text { Via de } \\
\text { Administração } \\
\text { da Droga }\end{array}$ & $\begin{array}{c}\text { Tempo de } \\
\text { Abstinência } \\
\text { Atual }\end{array}$ \\
\hline$\overline{\mathrm{AM} 1}$ & $15-18$ & $\begin{array}{l}\text { álcool maconha } \\
\text { cocaína }\end{array}$ & Oral inalada & 2 anos \\
\hline RM2 & $14-16$ & $\begin{array}{l}\text { álcool cocaína } \\
\text { maconha heroína e } \\
\text { medicamentos }\end{array}$ & $\begin{array}{l}\text { Oral inalada } \\
\text { injetável }\end{array}$ & 30 dias \\
\hline RM3 & $14-14$ & $\begin{array}{l}\text { álcool maconha } \\
\text { cocaína crack e } \\
\text { medicamentos }\end{array}$ & Oral inalada & 20 dias \\
\hline AM4 & $14-18$ & álcool cocaína crack & Oral inalada & $\begin{array}{l}1 \text { ano e } 7 \\
\text { meses }\end{array}$ \\
\hline$\overline{\text { AM5 }}$ & $11-13$ & $\begin{array}{l}\text { álcool inalantes } \\
\text { maconha cocaína } \\
\text { medicamentos }\end{array}$ & $\begin{array}{l}\text { Oral inalada } \\
\text { injetável }\end{array}$ & 4 anos \\
\hline AM6 & $14-14$ & $\begin{array}{l}\text { álcool maconha } \\
\text { inalantes }\end{array}$ & Oral inalada & 2 anos \\
\hline RM7 & $11-15$ & $\begin{array}{l}\text { álcool cocaína crack } \\
\text { maconha inalantes }\end{array}$ & $\begin{array}{l}\text { Oral inalada } \\
\text { injetável }\end{array}$ & 5 meses \\
\hline$\overline{\mathrm{AM} 8}$ & $14-17$ & $\begin{array}{l}\text { álcool maconha } \\
\text { cocaína inalantes } \\
\text { medicamentos }\end{array}$ & Oral inalada & $\begin{array}{l}2 \text { anos e } 5 \\
\text { meses }\end{array}$ \\
\hline$\overline{\text { RF9 }}$ & $14-15$ & $\begin{array}{l}\text { álcool maconha } \\
\text { cocaína }\end{array}$ & Oral inalada & 2 meses \\
\hline RF10 & $15-16$ & $\begin{array}{l}\text { álcool cocaína } \\
\text { maconha inalantes } \\
\text { medicamentos }\end{array}$ & Oral inalada & 2 meses \\
\hline$\overline{\mathrm{AF} 11}$ & $14-26$ & $\begin{array}{l}\text { maconha cocaína } \\
\text { medicamentos } \\
\text { inalantes }\end{array}$ & $\begin{array}{l}\text { Oral inalada } \\
\text { injetável }\end{array}$ & $\begin{array}{l}1 \text { ano e } 5 \\
\text { meses }\end{array}$ \\
\hline RM12 & $13-13$ & $\begin{array}{l}\text { álcool maconha } \\
\text { cocaína crack }\end{array}$ & Oral e it & 20 dias \\
\hline
\end{tabular}

pósito dessa pesquisa, foi adotado como critério para constituição do grupo dos abstinentes uma remissão completa no uso de drogas igual ou superior a um ano. Em contrapartida, para o grupo de casos de fracasso, a recaída teria ocorrido, preferencialmente, nos últimos seis meses. $\mathrm{O}$ critério utilizado para composição do grupo foi o da seleção deliberada (Morse, 1994). Assim, a intencionalidade e a conveniência do pesquisador foram os principais critérios de escolha das unidades representativas. A heterogeneidade dos participantes da pesquisa foi proposital, para ressaltar o espectro de variações possíveis com relação ao problema em estudo.

\section{Instrumentos e Procedimentos}

Foram utilizados dois roteiros de entrevista, um para os casos de abstinência e outro para os casos de recaídas. Os roteiros eram predefinidos e de sequiência flexível, permitindo ao entrevistador a colocação de diferentes perguntas e a verificação imediata de sua compreensão sobre o que estava sendo dito. Em geral, perguntava-se sobre a aproximação e envolvimento com as drogas, sobre a decisão de buscar ajuda e sobre situação atual, diferenciado-se então recaídos de abstinentes. A flexibilidade da entrevista deu ao entrevistado a liberdade de trazer temas e considerações de seu pró- 
prio interesse. Os roteiros foram elaborados de acordo com recomendações para entrevistas com abusadores de drogas (Craig, 1991). Contudo, algumas modificações foram necessárias para atender aos propósitos deste estudo. As entrevistas foram realizadas em entidades de apoio e tratamento, consultório de psicologia e residência dos informantes. O tempo de duração era de aproximadamente uma hora. Após a entrevista, os participantes preenchiam um breve protocolo para informações demográficas. Os informantes assinaram termo de consentimento informado em conformidade com princípios éticos de investigações científicas envolvendo seres humanos (Barker, Pistrang \& Elliot, 1994; Robson, 1993). ${ }^{3}$

\section{Resultados}

A análise qualitativa que será apresentada segue a tradição da pesquisa fenomenológica nos termos definidos por Merleau-Ponty (1945/1996). Como tal, ela se apresenta como um exercício de reflexão sistêmica e sistemática. A descrição, ou primeira reflexão fenomenológica, tem o objetivo de:

Restituir à coisa sua fisionomia concreta ... reencontrar os fenômenos, a camada viva através da qual primeiramente o outro e as coisas nos são dados, o "sistema Eu-outro-as coisas" no estado nascente, despertar a percepção e desfazer a astúcia pela qual ela se deixa esquecer enquanto fato e enquanto percepção, em benificio do objeto que nos entrega e da tradição racional que o funda. (Merleau-Ponty, 1945/1996, pp. 89-90)

A redução ou segunda reflexão sistemática foi definida por Merleau-Ponty (1945/1996, p. 94) do seguinte modo:

Depois de ter reconhecido a originalidade dos fenômenos em relação ao mundo objetivo, como é por eles que o mundo objetivo nos é conhecido, a reflexão psicológica é levada a integrar aos fenômenos todo o objeto possível, e a investigar como ele se constitui através deles.

Por fim, a interpretação fenomenóligca é, como disse Merleau-Ponty (1945/1996, p. 530): "pensar o pensamento [e] adotar em relação a ele uma atitude que primeiramente nós aprendemos a adotar em relação às "coisas". É o momento em que o pesquisador assumi uma atitute crítica à evidência e à compreensão que ele tem dela. Prosseguindo com Merleau-Ponty, "não é o um caso se a própria evidência pode ser posta em dúvida, é que a certeza é dúvida, sendo retomada de uma tradição de pensamento que não se pode condesarse em verdade evidende sem que eu renuncie a explicitá-la". A seguir serão apresentados os procedimentos operacionais para a elaboração da descrição, da redução e da interpretação.

As entrevistas (evidências) foram transcritas literalmente e analisadas em dois níveis. O primeiro nível constou de três passos: definição de unidades mínimas de sentido, iden-

3 Os roteiros das entrevistas ou mesmos as transcrições podem ser obtidas junto aos autores. tificação de temas relevantes e preparação de síntese compreensiva para cada entrevista (Gomes, 1998). A síntese compreensiva é a elaboração de um resumo exaustivo para cada entrevista, evitando-se a interferência dos valores do pesquisador. Em outras palavras a síntese compreensiva é a ampreensão do sentido de relevância e abrangência contido nas palavras usadas nas entrevistas. A especificação temática referiu-se à identificação do fenômeno enquanto estrutura, isto é, padrões que caracterizavam modos de relação de um corpo-sujeito com o ambiente, com o outro e consigo mesmo (Banister, Burmom, Parker, Taylor \& Tindall, 1994; Forghieri, 1984). No segundo nível, as entrevistas foram comparadas entre si tendo-se como base as especificações temáticas de cada uma. $\mathrm{O}$ interesse foi compreender a abrangência de cada tema, considerando as contribuições de cada entrevista como possibilidade e não como freqüência de ocorrência. $O$ resultado desta análise foi a aglutinação dos temas unitários tendo em vista as três grandes questões da pesquisa: 1) Tentativas de Recuperação, 2) Experiência da Abstinência, e 3) Experiência da Recaída. Deste ponto em diante, cada tema constituiu-se numa descrição oferecida para análise. Desta forma, a ordem de exposição e análise passou a ser a seguinte: descrição (de que trata o tema), redução (quais são as partes essenciais que devem ser amplificadas para análise, segundo critério do pesquisador), e interpretação (quais os aspectos críticos que aparecem na comparação entre a descrição e a redução, e como podem ser compreendidos).

A primeira unidade temática, da análise, reúne depoimentos de todos os informantes para focalizar o contexto da aproximação, o envolvimento com as drogas e as tentativas de recuperação. Os outros dois temas concentram-se nos relatos respectivos dos casos de abstinência e de recaída. Os aspectos técnicos e conceituais da análise reflexiva serão retomados durante a exposição. A descrição será ilustrada com breves excertos extraídos dos depoimentos, inseridos de forma a não violentar o fluxo da narrativa, isto é, eles estão colocados logo após o texto de descrição ou análise. Os excertos são identificados em formas abreviadas tais como AM1 ou RF9, sendo que a primeira letra refere-se a situação de Abstinência ou Recaída, a segunda ao sexo do entrevistado (M - masculino, $\mathrm{F}$ - feminino). O número refere-se à ordem seqüencial de realização das entrevistas.

\section{Primeiro Tema: Tentativas de Recuperação}

\section{Descrição}

As experiências de aproximação inicial com substâncias psicoativas foram, para os homens, a facilidade de se obter bebidas alcóolicas no ambiente familiar, a curiosidade, a necessidade se ser aceito na turma de amigos, e dificuldades no relacionamento familiar. Para as mulheres, as experiências foram as mesmas, com exceção da oferta de bebidas alcóolicas em casa. Em contrapartida, elas indicaram ter acesso fácil a substâncias ilícitas, geralmente envolvendo traficantes e companheiros usuários. O espaço e tempo percorri- 
dos da experimentação até a constatação de que necessitavam da droga foi muito variável. Os entrevistados referiram que esta consciência ocorreu após três meses de uso ou muito recentemente, mesmo em trajetórias de abuso de drogas superior a dez anos. A procura por recuperação foi desencadeada por experiências críticas como situações de desamparo e debilidade física, ocorrências legais, e revitalização de laços familiares.

As situações de desamparo estão associadas ao conflito inicial entre estes jovens e suas famílias. A escolha pela droga implicou em sair de casa e ir viver por conta, mesmo que para tanto tivesse que morar na rua. No entanto, a debilidade física decorrente da não alimentação e do uso crônico de drogas desencadeou a solicitação de apoio dos familiares, tantas vezes oferecido mas até então desprezado.

AM1: "Nos últimos três meses eu morei na rua. Eu não tinha o que comer, eu roubava direto. Eu roubava e usava drogas e dormia em qualquer lugar, na porta de boteco. Um dia, eu tava muito mal, fui pedir comida na minha mãe e a minha mulher veio lá e pediu se eu queria ajuda”.

AM5: "Eu não tive escolha, ou eu buscava ajuda, ou eu morria. Foi um beco sem saida. Eu só busquei ajuda depois que eu não tinha mais dinheiro e eu não tinha mais alternativa, se eu tivesse alternativa, eu continuaria usando a droga".

O envolvimento em ocorrências policiais serviu para uma retomada de posição em relação a si mesmo.

RM7: “Eu não queria ajuda nenhuma! (...) Até que aconteceu, bem dizer, um roubo que eu fiz, o estelionato na conta da minha mãe e ai o juiz determinou: 'Tu vai para a reunião e vai assinar o livro do poder judiciário'. Ai eu ia toda terça-feira mas, sem vontade nenhuma de ir lá. Foi, foi, que eu fui gostando...".

RM12: "Quando tu chega no fundo do poço. E eu cheguei lá. Eu tava sendo mal visto pelos outros e pela minha própria família (...). Eu conheço um brigadiano (...) ele me conhece, me vê na rua e vem em cima de mim. Aquele dia eu tava drogado, me estourei com ele e dei um soco, depois fui parar na delegacia e apanhei um monte, um monte mesmo. Ai eu pensei: - Não vou mais usar droga pro resto da minha vida”.

A família e seus vínculos também serviram como base para a reestruturação da vida destes jovens, motivando-os a buscar sua abstinência e recuperação:

AM4: "O nascimento da minha filha foi muito importante e além disso mais uma oportunidade que eu pudesse me dar para voltar a viver, ter uma vida normal".

A manutenção do propósito de manter-se longe das drogas foi muito difícil. A experiência de abstinência levava a instabilidade decorrente da mudança de vida e ainda trazia novos problemas, como angústia e depressão. A própria situação de abstinência servia como estímulo para o retorno às drogas, pois era nas drogas que encontravam alívio e os meios para enfrentar ou fugir dos problemas. Vejamos os excertos:

RM2: "Aqui nesta casa de recuperação eu estou há 18 dias e sem usar há 30 dias. Mas ainda é difícil me imaginar que eu vou sair daqui e não vou poder beber, fumar maconha, voltar para a turma (...). Está sendo um período de muita angústia: é ressentimento do passado, raiva do presente e tu não sabe o que vai ser do futuro."

AM8: "Quando tu ficas sóbrio, os problemas começam a aparecer. Tu sempre teve os problemas, mas só não tinha coragem de pensar neles. Dai tu bebias ou usava drogas e amortecia os problemas."

Foram reconhecidos como fontes de apoio para a recuperação: a família, os grupos de auto-ajuda, o convívio e troca de experiências com amigos recuperados, a religião, e o acompanhamento psicológico. Pessoas de referência no ambiente familiar como pais, tios e esposas foram identificadas pelos informantes como suporte positivo na reabilitação.

AM6: "Minha tia chegou e pediu o que eu tava precisando [a tia o encontrou furtando fitas de vídeo em sua loja]. Eu disse prá ela que não tava mais agüentando (...) Só que a ajuda dela seria muito diferente do que eu tava pensando, eu pensei que ela ia dar dinheiro para ir comprar, só que veio totalmente diferente, de uma forma que ajudou bastante, me deixou numa fazenda. (...). Foi ela que me ajudou até hoje, ela e meu tio trabalham na [instituição y] são voluntários”.

O grupo de auto-ajuda trouxe novas possibilidades de existência através do reconhecimento das vantagens de viver em abstinência.

AF11: "Nas reuniões, aqui, eu vi o brilho das pessoas nos olhos, como é bom tá de 'cara', que a vida pode ser boa de 'cara' (...). Eu vi pessoas aqui que eu nunca esperava que iriam se recuperar, eu vi um amigo meu, que era uma pessoa usuária terrivel, e eu vi ele ali, fazia dois anos que ele estava sem usar drogas. -'Pô, se este maluco pode, porque eu não posso?'.'

$\mathrm{O}$ apoio de colegas recuperados pode prevenir possíveis recaídas.

AM8: "Eu tive tratamento psicológico com a C. lá na [Instituição x] um tempo na [Instituição y] e apoio de colegas em geral. Um liga para o outro dizendo que não está bem, pede ajuda, ou um colega te telefona dizendo que está mal e quer conversar. Um dia eu liguei para um colega meu, dizendo que eu estava mal, conversei com ele e fiquei bem."

A importância do acolhimento, do acompanhamento técnico e da religião como fonte de esperança no processo de recuperação também foi reconhecida.

RM7: "A [Insituição y] foi um lugar que me acolheu, hoje eu vejo que se não fosse por eles, por tanta insistência, tanto a coordenadora quanto a psicóloga ligavam altas horas da noite para a minha casa, para saber como eu estava...Nunca ninguém tinha feito isso, nunca ninguém tinha se importado tanto comigo que nem eles se importaram."

RF10: “Tu já começa a crer em alguém, a crer em Deus porque tu não acredita em nada; Se tu não acreditar em nada, não tem como tu melhorar...". 
Em contraste, situações vivenciais em grupos de autoajuda foram questionados pois traziam lembranças e desejos de usar drogas. Geralmente, estas situações apresentavam-se associadas as verbalizações dos próprios membros do grupo sobre suas últimas ingestões de drogas.

RF9: "Não sei se ajuda! Um dia tava eu e a F. numa sala, e nós começamos a conversar sobre o que a gente fazia e eu fiquei fissurada! Eu estava me mordendo de vontade de usar drogas".

A experiência de passagens por clínicas de desintoxicação deixou a convicção, nos entrevistados, de que apenas medicação não contribui para a recuperação.

AM1: "Aí eu fui para uma clínica de desintoxicação. Ai eu troquei uma droga pela outra. Deixei de usar a minha preferida, a cocaina, para usar amplictil, tegretol...".

AF11: "O que eles faziam era me dopar. (...) Tanto que eu não engordei, eu enchi, fiquei inchada, não falava, babava, ficava toda torcida, me achava horrivel, odiava o psiquiatra, achei horrivel o tratamento lá dentro, eles não sabiam tratar uma pessoa drogada, não é com drogas".

\section{Redução}

A análise da descrição, que focalizou as circunstâncias e os contextos associados às tentativas de recuperação, pode ser subdividida em quatro partes: 1) experiências críticas que mobilizaram para a recuperação; 2) abordagens e recursos utilizados na recuperação; 3) dificuldades para se manter longe das drogas e 4) experiências de desintoxicação. A redução analítica colocará entre parênteses as partes 1, 2, e 4, focalizando então a parte 3: dificuldades para se manter longe das drogas. Na verdade, trata-se de uma condição essencial para a recuperação. Sem abstinência não há recuperação. Pergunta-se, então, qual o significado da transição da ingestão para a abstinência? Uma frase de um dos entrevistados traz todo o imbricamento existencial deste momento:

AM5: "Eu gostava muito de fumar quando eu lia, quando eu escutava música, antes de jogar futebol, antes de correr, antes de namorar, antes de fazer sexo, eu gostava de fumar antes de fazer tudo".

Bucher (1996) definiu o ficar "abstinente" para estes jovens como um retrocesso à situação anterior ao uso. Era um retorno aos mesmos problemas, agora intensificados pela rotina centrada na droga. Abster-se da droga, portanto, pode ser entendido como uma ruptura no sentido da existência. É o mesmo que se deparar com o vazio, com o Nada. Ao suprimir-se a incorporação do tóxico, é necessário enfrentar os mesmos problemas dos quais estava tentando fugir: fragilidade, vivências de vazio, déficit crônico de estima, e depressão (Kalina, 1999).

AM5: "Então, não é só o fato de parar de usar as drogas, éo fato de entender todo o meu mundo de droga, ir lá na ferida e trazer tudo de volta, recomeçar tudo de novo, eu tenho que começar, eu tenho que voltar a viver, a fazer as coisas, a conviver com as pessoas e aprender a amadurecer".

A abstinência abstinente significava mudança em todas às áreas de impacto da dependência, exigindo grande esforço para resituar-se no mundo e encontrar nova identidade.

AM1: "Quando passou os três meses eu encontrei uma pessoa lá dentro (na comunidade terapêutica) que eu não gostei de ter visto: eu mesmo. Eu me encontrei e vi o que realmente eu era (...). Eu fiquei assustado com o que eu tinha me tornado. E ai eu passei a mudar o meu comportamento."

\section{Interpretação}

O confronto entre as partes que estavam entre parênteses (descrição) com a parte focalizada na redução mostra-nos um paradoxo. A droga que viabilizava a existência destes jovens aproximava-os de práticas auto-destrutivas, podendo culminar na morte. A idéia da morte tem sido interpretada (Oliveira, 1991) como uma função estruturante na personalidade adolescente, com o argumento de que é no confronto com a morte que se descobre o valor da vida (Kalina, 1997). Desse modo, parece que somente compreendendo a possibilidade da morte como única alternativa para suas existências é que estes jovens aceitaram enfrentar a realidade e as suas consequiências, sejam estas dolorosas ou não.

AF11: "Hoje em dia, a gente sente a dor da vida, encara ela. Essa é a maior dificuldade. É tu encarar a dor da vida, de cara! E dizer que eu não quero mais, é só por hoje, mas eu não quero mais droga".

O grande desafio da recuperação é substituir a rotina centrada na droga por novos hábitos evitando o retorno aos comportamentos destrutivos anteriores. Na implementação dessa mudança, o ambiente social exerceu uma poderosa influência na recuperação destes jovens. A influência mostra-se no restabelecimento do convívio familiar, nos encontros com colegas recuperados e no apoio de profissionais especializados. Note-se que o termo usado foi reestabelecer, que quer dizer uma reaprendizagem para viver sem drogas e encontrar sentido em atos corriqueiros e habituais.

Entre as experiências oferecidas para favorecer a recuperação, duas receberam comentários negativos: grupos de auto-ajuda e desintoxicação. Em situações de grupo de auto ajuda, relatos ou conversas sobre memórias prazerosas relacionadas à ingestão de drogas foram percebidas como fazendo retornar o desejo de ingestão, facilitando a recaída. Sabe-se que o uso de grupos requer cuidados especializados pela imprevisibilidade de atos inter e intrapessoais desencadeados pelo processo grupal (Gomes, Teixeira \& Borges, 1998). Quanto à desintoxicação, os depoimentos obtidos indicaram que a experiência do tratamento foi percebida como muito dolorosa e desnecessária, sendo muito criticada. O uso de medicação no tratamento da drogadição tem crescido nos últimos anos (Litten \& Allen, 1998), no entanto o papel destes tratamentos ainda é limitado (Kranzler, Amin, Modesto-Lowe \& Oncken, 1999). Caso o uso de medicação seja imprescindível espera-se que haja supervisão cuidado- 
sa quanto a implicações psicológicas que possam prejudicar a percepção desta modalidade de tratamento, como sugerem os depoimentos recolhidos para esta pesquisa.

\section{Segundo Tema: Experiência da Abstinência}

\section{Descrição}

A primeira análise destacou dois momentos distintos na experiência da recuperação: as dificuldades para se atingir a abstinência e as condições desejáveis para sua manutenção. Mesmo que o início da abstinência esteja associado ao enfrentamento de dificuldades e responsabilidades anteriormente ignoradas, alcançar a abstinência é apenas o primeiro passo para a recuperação. Requer uma profunda revisão de condições ambientais, reestruturação de atividades e revitalização de interesses.

AM5: "Depois que eu sai de lá, o tratamento terminou, mas a recuperação continuou. Então foi aí que eu me vi na rua de novo, foi a segunda parte da recuperação. Quando eu estava lá dentro, não sofri, me senti amado, me senti importante. Mas de repente, eu saio dali, mas não sou mais ninguém, quem sou eu?".

O mais difícil, para estes jovens, não foi atingir a abstinência. Foi dar continuidade ao processo de mudança. Aspectos vitais no processo de recuperação, apontado por estes jovens, foram: resgate dos vínculos familiares, reencontro da auto-estima e redescoberta das relações interpessoais.

AM4: "A minha vida, a minha esposa, a minha família, a minha filha. Se eu continuasse usando drogas, que moral eu poderia dar a minha filha? Nenhum. Eu pretendo ser um exemplo para ela”.

AF11: "A chave mesmo é o meu filho e a mim, a minha vida. Eu acho que eu mereço, né? Mereço viver, mereço uma oportunidade".

AM5: "Sabe o que eu tenho de mais valor hoje, são meus amigos, a minha família, a pessoa que eu gosto hoje, que é minha companheira e está do meu lado. É o que eu tenho de mais precioso, é o cultivo das coisas que eu tenho. Essas coisas são essenciais, que ao saírem da minha vida não tem mais o sentido da vida (...). Isso tudo é o que eu quero resgatar, que só de pensar me dá muito prazer".

O reconhecimento e a conscientização dos problemas decorrentes da dependência exerceram papel fundamental na manutenção da abstinência:

AM6: "Acho que...é o não querer mesmo mais usar (...) Eu não quero mais usar em hipótese alguma que seja, eu tenho que saber que eu já sei o que pode me acontecer; Eu tenho sempre comigo, a gente diz assim, a lata de lixo que é o destino que a gente fez. Então, eu já tenho uma consciência de que eu não quero mais usar, aconteça o que acontecer".

Manter o tempo ocupado com alguma atividade prazerosa que substitua a droga e reforce, ainda mais, a decisão pessoal de não reincidir no seu consumo foi ressaltado pelos jovens como fator importante para permanecer abstinente.
AM8: "Eu sempre mantenho o meu tempo ocupado, não tenho como pensar em drogas. Não adianta tu só parar de beber, é a mesma coisa que tu tampar uma garrafa e botar embaixo do braço, uma hora ou outra tu vais beber. Tem que arrumar um trabalho, uma atividade, até trabalhar ali no grupo".

O envolvimento na recuperação de outros dependentes, seja através dos grupos de auto-ajuda ou monitorando comunidades terapêuticas foi considerado importante para a abstinência.

AM1: "Hoje, o que me mantém de pé é viver o que eu estou vivendo, a minha recuperação. Porque eu continuo num ambiente terapêutico e faço aquilo que gosto. Quando eu falo para alguém, eu reafirmo minha decisão pessoal".

Práticas religiosas serviram de apoio para a recuperação.

AM5: "Em princípio a oração, a ação e o fato de eu estar participando do grupo. É o fato de eu levar aquilo que eu sei para as pessoas partilharem. A partilha, o grupo de ajuda, as reuniões que muitas vezes eu faço fora, testemunho (...). O estudo do meu trabalho, a leitura de muitas coisas que me enriquecem como pessoa, os meus amigos".

A percepção de mudanças positivas obtidas com a abstinência reforçam a perseverança pela recuperação.

AM6: "Mudou, depois que eu estou em abstinência, mudou assim radicalmente. Eu não trabalhava, no tempo de ativa, eu não trabalhava, não estudava, e não fazia uma série de coisas, só sabia era usar. Hoje, eu trabalho, estudo, há pouco tempo comecei a namorar, a amizade totalmente mudou. Hoje, eu tenho verdadeiros amigos no meu trabalho, em casa também, o meu relacionamento em casa está muito melhor".

AM4: "Mudou tudo, é impressionante! A comunidade te vê com outros olhos, eu posso andar de cabeça erguida, não preciso fugir de ninguém, nem de mim mesmo...".

AF11: "Acho que mudou assim... a minha concepção da vida. Hoje, eu vejo que sou capaz de viver, de ter objetivos. Se eu não conseguir hoje, eu sei que amanhã eu vou tentar de novo! (...) Meu modo de ser mudou, antes eu era totalmente desleixada, não tava nem aí para a minha aparência. Hoje, eu tenho uma auto-estima, hoje, eu gosto de mim”.

Os informantes abstinentes indicaram estarem envolvidos em planos concretos como retornar aos estudos, ao trabalho, ao convívio familiar e dispostos a se manterem afastados do recurso químico quando tiverem que enfrentar dificuldades.

\section{Redução}

A redução será dirigida, em primeiro lugar, para a explicitação dos temas que aparecem imbricados na descrição, a saber: reformulação da visão de mundo, condições ambientais, reencontro com o outro e o reencontro consigo mesmo. A seguir, os mesmos temas serão contrastados com a condição básica de mobilização pessoal para a mudança. A análise dirige-se, desta forma, para a superação das questões de existência envolvidas no consumo de drogas e na 
decisão pela recuperação. Tanto a angústia como a liberdade fazem parte da condição humana. A angústia aumenta a partir do momento em que são questionados os valores que, em liberdade, o ser humano pode experimentar modificálos. A escolha de valores apresenta-se tanto na conquista da liberdade como na submersão na angústia. É através de escolhas que o ser humano constrói o seu projeto e projeta a sua própria imagem diante do mundo.

O consumo crônico e regular de drogas apresenta-se como um valor regulador de existência e foi decorrência de escolhas de vida. Para os entrevistados, os processos perceptivos e expressivos estavam sendo mediados por substâncias químicas. Ao ser retirada, a droga deixou um vazio. Um vazio amplificado pelo isolamento. Os relatos indicavam que as drogas levaram a um estranho isolamento. Bucher (1996) interpretou este isolamento como um distanciamento do convívio social em busca de uma felicidade que viria pelo esquecimento e pelo afastamento. O prazer solitário estabelecido entre estes jovens e as drogas pode ser entendido como uma espécie de completude, onde o encontro com o outro ficou impossibilitado.

RM7: “A mudança na minha vida é que eu me afastei de todo mundo que gostava de mim. Me afastei da familia, vizinhos, dos bichos que eu tinha. Eu me afastei completamente de todo mundo. (...) Mesmo quando eu estava com o traficante, eu não usava a droga. Eu usava a droga quando eu estava sozinho, no meu canto, do meu jeito".

Havia uma relação entre a procura do prazer solitário proporcionado pela droga e a percepção de vazio de vida. Quanto mais a vida era percebida como vazia mais a droga se fazia necessária. Por outro lado, a percepção de vida vazia especifica a expressão de desencontro consigo mesmo.

AF11: "Porque com a droga tu não tem objetivo nenhum, tu nem sabe mais de ti, o que tu tá fazendo no mundo."

AM5: "Eu tinha dentro de mim muita tristeza, hoje eu sei, na época não, eu não conseguia ordenar pensamento algum. Mas, voltando ao passado, eu via que quando eu estava triste, eu me sentia sozinho, eu ia numa festinha e começava a beber."

AM5: "Eu posso usar droga para sair desta realidade, para me sentir uma pessoa diferente, me sentir aquilo que eu não sou. Era como se eu rejeitasse aquilo que eu era e me tornasse outro personagem, de uma outra história."

A condição básica para se afastar completamente das drogas era estar predisposto a mudar de vida e ter a visão de que, longe de trazer soluções, as drogas traziam sérias consequiências para si e para o relacionamento com o mundo.

RF10: "Só que tu vai lá e não muda. Se tu não quer mudar, tu não muda. Tem que ter força de vontade."

A mudança na vida destes jovens parece ter envolvido, além de muita paciência e aceitação do sofrimento, a busca de alternativas saudáveis, e a escolha de novos posicionamentos diante da vida. Passou pela decisão de cortar o contato com antigos companheiros e evitar o contexto favore- cedor do consumo de drogas. Surgiu, então, a necessidade de novos encontros interpessoais que foram atendidos pela família, e por amigos não-usuários ou recuperados. Neste sentido, os grupos de auto-ajuda foram importantes para a restauração das ligações sociais, promoção de vínculos saudáveis, e reafirmação na esperança da recuperação.

RM12: "Eles falam em coragem, ter fé, aceitação, bondade. (...) Eu gosto mesmo dos monitores daqui, eles sabem muito bem ajudar as pessoas".

Os grupos coordenados por dependentes recuperados foram mencionados como suporte importante e caracterizam-se por serem o ambiente ideal para a abordagem e discussão dos problemas relacionados a abstinência e de como enfrentá-los:

AF11: "É onde eu exponho meus sentimentos para as pessoas que também passam pelo mesmo problema e tem uma visão, porque não adianta chegar para a minha mãe e dizer: - 'Oh! mãe, hoje eu não tô legal, tá me batendo uma fissura'. Ela não vai entender isso."

Salgueiro (1995) enfatizou que a disciplina, as rotinas específicas e o envolvimento com as pessoas quando incorporadas ao "dia-a-dia" facilitam que o dependente químico ancore sua recuperação e estabeleça um novo e gratificante estilo de vida. No entanto, adverte que os fatores que mantêm a abstinência e o processo de mudança são muitos e difíceis de discriminar. Neste processo de mudança, foi citado pelos jovens, a busca da religiosidade. A religião é vista como algo que dá sentido e parece contribuir para o esforço de alcançar níveis mais elaborados de relacionamentos com o mundo externo.

AM5: "Eles ensinam os doze passos, o objetivo dos doze passos é o despertar espiritual, o despertar para alguma coisa mais elevada, uma razão de vida, uma ideologia, uma convicção, um objetivo, teu sonho, sei lá. Até ter Deus na vida, alguém que te ilumine, que no momento do desespero esteja perto de ti.",

Nesse sentido, a religião parece auxiliar estes jovens a se religarem com o mundo e consigo mesmo. Para Kalina (1999), os critérios de cura são ideológicos. Curar, no seu entendimento, é oferecer um modelo de vida em troca de outro, a partir da aplicação de uma determinada escala de valores. Enfim, a cura deriva-se de uma concepção específica da liberdade, isto é, do sentido da vida.

Em suma, os elos essenciais de experiências que favorecem a abstinência estão nos esforços bem sucedidos de tomada de decisão e replanejamento ambiental e ocupacional. Este replanejamento deverá incluir a revitalização de relações interpessoais que por conseguinte facilitará o reencontro consigo mesmo nesta nova condição de existência.

\section{Interpretação}

É nas situações-limites como morte, sofrimento, culpa e loucura que se constrói um conjunto de significações refe- 
rentes à condição humana de um corpo sujeito situado e sempre diante de limites. É na ruptura, na conscientização do fracasso, no confronto entre o que se quer e o que não se quer, que parece emergir a compreensão do possível, do projeto construtivo viável. As angústias destes jovens frente à experiência de vazio ou morte iminente parece ter sido o ponto de partida para a resignificação das suas existências. Note-se, aqui, a analogia com a segunda condição para remissão estável de consumo referida por Vaillant (1997), ou seja, a reação por mudança diante da angústia de sentir-se no fundo do poço. A promoção da abstinência permitiu que estes jovens readquirissem a capacidade adaptativa, enquanto presença transformadora, frente às diversas situações da vida. A experiência da abstinência pode ser interpretada como um esforço assistido de reconhecimento do problema aditivo, de retorno à família, de recuperação de auto-estima, da evitação do contexto favorecedor da adição, do envolvimento em trabalhos de recuperação de outros dependentes e, por fim, de um sentido prospectivo de existência. Note-se, aqui, a analogia com a terceira condição para remissão estável de consumo referida por Vaillant (1997), ou seja, romper com hábitos enraizados.

\section{Terceiro Tema: Experiência da Recaída}

\section{Descrição}

A recaída é definida como um retorno ao uso de drogas após um determinado período de abstinência. Entre os entrevistados, o menor período de abstinência foi de duas semanas e o maior de dois anos. A experiência de recaída mostrou-se associada às seguintes situações: falta de apoio familiar, falta de acompanhamento apropriado, envolvimento com antigos amigos usuários, uso de bebidas alcóolicas, necessidade de aprovação social e frustrações diante de circunstâncias adversas.

Os jovens relataram episódios em que a mãe, o pai ou ambos, procuravam esconder qualquer evidência que indicasse que eles estavam dependentes de drogas. Quando decidiram agir, o caso já era muito grave.

RM2: "Minha mãe sempre tentou botar panos quentes. Era do tipo de jogar as seringas sujas fora e as novas guardar. Guardava a maconha no meu armário. Quando ela viu que o problema era sério, ela pegou pesado e me encaminhou para a psicóloga."

RM3: "Meus pais são enfermeiros (...) Até pouco tempo, eles não queriam acreditar que a gente usava drogas. Eles se manipulavam também para poder acreditar na gente. Mesmo achando a droga dentro de casa, eles acreditavam que era a última vez e que nós tínhamos parado de usar. Só que voltava tudo como era antes."

RF9: "Agora o que eu fazia lá, eu era quase um monstro, batia na minha mãe, eu escondia a droga e depois não sabia onde estava, quebrava tudo. Enchia a casa de gente, fazia a maior zona. Mas eu não me arrependo do que eu fiz para a minha mãe porque ela não acorda nunca! Quando meu pai ligava para lá pedindo como eu estava, ela dizia que eu estava bem. Escondia todos os problemas."

Conflitos familiares estavam associados à procura por drogas e à recaída.

RF10: "Mesmo indo no [Instituição y], meu pai não me ajudava, não me dava apoio em nada. Minha mãe me ajudou a partir do momento que ela começou a ir no [Instituição y] (...) Meu pai era alcoólatra antes, às vezes, ele se irritava com a minha mãe e batia nela (...) Dai ele começou a parar de usar álcool, parou de beber, e começou a ajudar mais a minha mãe, porque a minha mãe também...sofre um monte de depressão".

Os entrevistados reconheceram não ter forças para lutar sozinhos contra a atração e o impulso para o consumo.

RF10: "E pelo motivo assim de tu não conseguir parar sozinho. Tu sente dependência, fissura(...) Minha vida era assim...se eu não usar droga hoje, o que eu vou fazer? Nada! Eu não estudo, eu não trabalho, o que eu vou fazer? Nada! Eu tinha alguma coisa para fazer durante o dia que era conseguir dinheiro, que era correr atrás da droga."

RM2: "A abstinência sem acompanhamento, sem ajuda, termina com o cara! Eu definhei neste periodo: não comia mais, brigava, minha vida se transformou num caos. Ai tudo tava errado não pela droga, mas pela falta dela. Ai eu fui no bar e bebi para poder me acalmar."

A presença de amigos usuários foi descrita como um convite para a recaída.

RM3: "Geralmente, com amigos. Um camarada meu me oferecia. (...) Quando eles sabiam que eu estava sozinho em casa, eles davam uma paradinha por lá. É dificil porque quando tu tá tentando parar, sempre aparece algum na tua porta”.

O uso do álcool também foi associado a reincidências no consumo de outras drogas.

RF9: "Eu saio e fico pensando em beber. Só que é a bebida que chama a droga! Eu nunca penso em cheirar, a fissura em cheirar quem me dá é a bebida. Eu saio e sempre sem beber, é dificil."

RM7: "É aquele negócio: eu tô passando na rua, olho para um bar e vejo um tomando cerveja! Vejo televisão e passa um monte de mulher bonita e um cara 'fortão' tomando chope. Eu digo: - 'Meu Deus do Céu, porque eu não sou normal?'.'”

Recaídas ocorreram para evitar a desaprovação social. RF9: "Não era vontade, não era nada! Eu não queria ser 'careta' perto dele. Hoje eu vejo que não tem nada a ver! Foi para não fazer feio."

Fortes frustrações levaram à recaída como, por exemplo, rompimento de uma relação amorosa.

RM7: “A recaída veio de um relacionamento que não deu certo. (...) Hoje eu enxergo que não foi porque a E. (namorada) quis me deixar que eu recai e, sim, porque eu estava esperando um motivo e hoje eu vejo que foi muita falta de fé minha, de oração." 


\section{Redução}

As situações identificadas na descrição caracterizam-se por conjunturas paradoxais: a família que se perde na ambigüidade da proteção ilusória, da negação ou da absorção dos próprios conflitos; a amizade que traz a contradição do convite ao vício; e a falta de perspectiva diante da adversidade.

A situação familiar foi descrita pelos jovens com experiências de recaída como não favorecendo as condições de mudança. Kalina (1999) observou, na sua experiência clínica, padrões familiares que podem induzir os filhos à ingestão de drogas. São famílias caracterizadas por profundos sentimentos de abandono, vivências depressivas e incapacidade para dominar a ansiedade. Essas famílias negam ou mesmo excluem qualquer possibilidade de diálogo a respeito da droga. Por conseguinte, acabam reforçando os vínculos centrados na obtenção do consumo, deixando a droga como alternativa para que os filhos busquem integridade e identidade.

O uso do álcool e a fantasia de poder readquirir o controle sobre o seu consumo foi citado pelos informantes como uma das causas mais comuns de recaída. O uso inadequado das drogas é um problema de existência e um paradoxo social. A mesma sociedade que produz e promove o consumo condena o uso descontrolado ou o uso ilícito. Acontece que o uso próprio pode se transformar em uso impróprio e, provavelmente, em uso ilícito. O retorno do uso ilícito para o uso próprio já foi colocado como processo de reeducação desejável mas não se mostrou eficaz (Feix, 1996; Gossop, 1997; Ramos, 1997). Assim, sem assistência adequada (supervisão compulsória para Vaillant, 1997) é extremamente difícil a eficácia de qualquer tentativa de recuperação, como evidenciado nos depoimentos.

Neste contexto, as amizades imediatamente anteriores ao início da tentativa de recuperação apresentam-se como signos de dissonância. Em breve exercício imaginativo, o termo amizade pode ser substituído por palavras como companhia, apoio, confidência e cumplicidade. Entre adictos, o sentimento de aliança continua existindo no núcleo de uma amizade. É uma aliança adversa mas que existe na companhia, no apoio, na confidência e na cumplicidade do infortúnio. A tentativa de recuperação é um esforço para reversão de rumo. Significa uma ruptura radical com um ambiente que inclui o afastamento dos companheiros de uso e dos distribuidores da droga. O paradoxo está na contradição de identificar como amigos aqueles dos quais deve se afastar.

RM7: "Mas eu os considerava amigos, porque a gente convivia bem dizer juntos, cada um sabia das dificuldades do outro. (...) A minha maior dificuldade foi esquecer estas companhias. Qualquer bairro que eu entre em Caxias, eu conheço alguém."

Kalina (1999) advertiu que todo adicto, até prova em contrário, é um indutor ao consumo. Esta maneira de agir tem o significado de um ataque de inveja. Este fato se torna mais evidente quando o outro é um ex-adicto recuperado.
RF9: "Eu saio na rua para dar uma volta, eles vem me oferecer. (...) Eles ficam te cutucando, quando tu tenta parar....) A intenção é que eles tão na merda e querem que tu fique junto."

As dificuldades inerentes à recuperação fragilizam os esforços para mudança. As adversidades da vida cotidiana são percebidas com exagero, principalmente quando envolvem relações interpessoais. Sabe-se que o dependente tem uma incapacidade de tolerar frustrações e, neste enfoque, a recaída pode ser entendida como uma resposta ao não enfrentamento destas situações (Silva, Ferri \& Formigoni, 1995). Tem-se, assim, um circulo vicioso já que a tendência do indivíduo, após a recaída, é sentir-se fracassado e humilhado, o que contribui ainda mais para a manutenção do consumo.

\section{Interpretação}

É difícil descrever e imaginar o conjunto de situações que favorecem a quebra da abstinência (Rosenow, Niaura, Childress, Abrams \& Monti, 1991). A análise anterior aponta na direção da interpretação de Bucher (1996). Para o autor, o fenômeno moderno das drogas está situado no centro da sociedade e é produzido por ela em decorrência dos seus modos desequilibrados e injustos de organização, comunicação e valorização. No entanto, querer mudar o conjunto da sociedade e de suas formas de organização é um programa ideal e portanto utópico. Em uma outra perspectiva, podese argumentar que casos de dependência são situações que podem ser abordadas de modo pontual desde que sejam consideradas as implicações contextuais. A manutenção do consumo de drogas pareceu relacionar-se à falta de apoio familiar, de acompanhamento apropriado, de permanência no ambiente favorecedor da adição, na ausência de auto-estima e determinação. Confirmam-se, assim, as três situações primárias apresentadas na análise de recaída de Cummings, Gordon e Marlatt (1980), ou seja, a presença de estados emocionais negativos, de conflito interpessoal recente e de pressão social.

\section{Considerações Finais}

O estudo focalizou três temas relacionados à experiência da reabilitação em dependentes químicos: tentativas de recuperação, abstinência e recaída. As três análises representam apenas possibilidades de compreensão do problema. $\mathrm{O}$ estudo recorreu a falas procedentes de dependentes em busca de recuperação e deu espaço para que estas falas servissem de evidência descritiva e de interlocução analítica com a literatura. Neste sentido, atendeu a recomendação de Keen (1979) de que uma das contribuições do método fenomenológico é tornar explícitas aquelas idéias e suposições implícitas, com base nas quais responde-se e experimenta-se o cotidiano. O cotidiano, no caso, foi a tentativa de recuperação da dependência química.

A análise fenomenológica baseou-se em interpretações das reversões entre experiência consciente e consciência da 
experiência, como percebida pelos pesquisadores nas falas dos entrevistados. A reversão foi facilmente identificada nas diferentes falas. Por exemplo, falas sobre desamparo (viver na rua), constrangimentos com a lei (ser preso) ou função paterna (não estar em condições de criar um filho recémnascido) expressavam a percepção de uma situação que precisava ser revertida para outra, mediada por uma decisão, isto é, por uma tomada de consciência que é a reversão da experiência consciente (irrefletida) em consciência da experiência (refletida). O rigor reflexivo encaminhou a análise em desdobramentos repetitivos e circulares com o objetivo de amplificar o que era para ser tomado (movimento sinérgico). O exemplo desta circularidade está na comparação dos depoimentos de abstinência e recaída. Esses depoimentos aparecem em relações simultâneas de exclusividade e inclusividade, fazendo com que uma experiência seja o reverso da outra. Tomem-se, por exemplo, os seguintes constituintes experienciais da abstinência: determinação por mudança, apoio e estrutura familiar, grupos de auto-ajuda, mudanças de ambiente, novas redes de relações interpessoais e clareza de planos para o futuro. $\mathrm{O}$ oposto destes constituintes descreverá a experiência de recaída. As comparações identificam constituintes comuns e por isso inclusivos mas que são qualitativamente diferentes, por isso exclusivos.

Estudos (Bucher, Fares, Pelegrine, Menezes \& Carmo, 1995; Heather, 1992; Marlatt \& George, 1984; Sannibale, 1990) já constataram que a aderência aos programas de tratamento e aos procedimentos terapêuticos depende, ao menos em parte, da motivação para mudança e de condições estruturais de apoio. A relação entre constituinte (motivação para mudança) e contexto (condições estruturais de apoio) abre dois importantes flancos para críticas à compreensão do problema. São elas: motivação por mudança e clareza de planos para o futuro. A determinação por mudança é, na verdade, a conjunção entre consciência do problema e vontade de mudar. Sem atender a essa condição não será possível iniciar um projeto de mudança. Em contraste, sem definição de planos e ações concretas para realizá-los não há como sustentar a abstinência. A abstinência, como descrita, foi facilitada por um conjunto de apoios contextuais, como família, grupos e redes de amigos. Ora, pode-se interpretar que a dificuldade em esclarecer constituintes experienciais efetivos decorre da imbricação entre constituintes e contextos, que é a mesma imbricação entre Eu, Outro e Ambiente, ou entre objetividade e subjetividade (Gomes, Teixeira \& Borges, 1998). A imbricação apontada exerce uma função de via dupla rompendo com limites artificiais entre constituintes e contextos, e entre cultura (uso de droga) e natureza (dependência). Por via dupla entende-se a capacidade do sujeito modificar o objeto ou do objeto modificar o sujeito. No caso da dependência, o problema inicia com um objeto (droga) que transforma um corpo-sujeito em dependente. Em contraste, na recuperação espera-se que o sujeito modifique suas escolhas de objetos relacionais. No entanto, as combinações desejáveis para recuperação efetiva não podem se restringir a escolhas representacionais ou simbólicas. Requerem o desenvolvimento de recursos que provoquem e mantenham movimentos intencionais para a reabilitação, incluindo alterações concretas e objetivas para inserção de dependentes, combinadas com apoio e intervenção (vide Scivoleto, Henriques \& Ferreira, 1995). Exemplos de alterações concretas e objetivas presentes nas falas dos entrevistados foi a inserção de abstinentes em programas de recuperação de dependentes. Atendeu-se, com essa situação, necessidades de recomposição de auto-estima, apoio social, mudança ambiental, e planos concretos de ação. Em suma, criaram-se condições para que sentidos concretamente vividos obtivessem consolidação em projetos de vida realizáveis.

A referência negativa dos entrevistados às suas passagens por clínicas de desintoxicação merece atenção. Na percepção dos entrevistados o tratamento medicamentoso não favoreceu à recuperação. No entanto, o presente estudo não dispõe de dados para refletir e interpretar adequadamente as falas referentes a essas experiências, e deixa o problema como sugestão para futuros estudos. Recomenda-se, ainda, que próximos estudos concentrem-se na investigação de possibilidades e variedades da emergência motivacional para mudança e de modos compartilhados de desenvolvimento de objetivos de vida para dependentes em busca da reabilitação.

\section{Referências}

American Psychiatric Association (1994). DSM-IV: Diagnostic and statistical manual of mental disorders (4. ${ }^{\mathrm{a}}$ ed. revisada). Washington, DC: Autor.

Andreatini, R., Galduróz, J.C.F. \& Formigoni, M.L.O.S. (1994). Estudo da influência dos níveis de dependência e consumo na resposta ao tratamento de dependentes de álcool. Revista $A B P$ APAL, 16, 25-29.

Banister, P., Burmom, E., Parker, I., Taylor, M. \& Tindall, C. (1994). Qualitative methods in psychology. Open University Press Buckingham: Philadelphia.

Barker, C., Pistrang, N. \& Elliot, R. (1994). Research methods in clinical and counselling psychology. New York: Wiley.

Bertozzi, S.R. (1993). Por que as pessoas usam drogas. Revista Insight - Psicoterapia, 3, 22-23.

Bucher, R. (1996). Drogas e sociedade nos tempos da AIDS. Brasília: Editora Universidade de Brasília.

Bucher, R., Fares, A.T., Pelegrine, R., Menezes, R. \& Carmo, R.A. (1995). Avaliação qualitativa dos atendimentos [Resumo]. Em CETAD/UFBa (Orgs.) Seminário Internacional: $O$ Uso e o Abuso de Drogas , (p. 53). Salvador: CETAD/UFBa.

Craig, R. (1991). Abuso de substâncias. Em R.J. Craig (Org.), Entrevista clínica e diagnóstica (M. A. V. Veronese, Trad.) (pp. 175-193). Porto Alegre: Artes Médicas.

Cummings, C., Gordon, J. \& Marlatt, G.A. (1980). Relapse: Strategies of prevention and prediction. Em W.R. Miller (Org.), The addictive behaviors (pp. 31-56). Oxford, U.K.: Pergamon Press.

Feix, R. (1996). Drogas: Uso, abuso e dependência. Em B.B. Duncan, M. I. Schmidt \& E.R.J. Giugliani (Orgs.), Medicina ambulatorial: Condutas clínicas em atenção primária (pp. 537 550). Porto Alegre: Artes Médicas.

Edwards, G. (1997). Os Alcoólicos Anônimos como um espelho colocado diante da natureza. Em G. Edwards \& C. Dare (Orgs.), Psicoterapia e tratamento de adições (M.A.V. Veronese, Trad.) (pp. 201-217). Porto Alegre: Artes Médicas. 
Forghieri, Y. C. (1984). Fenomenologia e psicologia. São Paulo: Cortez.

Gomes, W.B. (1998). A entrevista fenomenológica e o estudo da experiência consciente. Em W.B. Gomes (Org.), Fenomenologia e pesquisa em psicologia (pp. 19-44). Porto Alegre: Ed. Universidade/UFRGS.

Gomes, W.B., Teixeira, M. \& Borges, M. (1998). Grupos homogêneos com obesos: Um estudo de caso. Em W.B. Gomes (Org.), Fenomenologia e pesquisa em psicologia (pp. 197-211). Porto Alegre: Ed. Universidade/UFRGS.

Gossop, M. (1997). Tratamentos cognitivos e comportamentais para o uso inadequado de substâncias. Em G. Edwards \& C. Dare (Orgs.), Psicoterapia e tratamento de adições (M.A.V. Veronese, Trad.) (pp. 146-158). Porto Alegre: Artes Médicas.

Gossop, M., Green, L., Phillips, G. \& Bradley, B. (1989). Lapse, relapse and survival among opiate addicts after treatment. British Journal of Psychiatry, 154, 348-353.

Grant, B.F. \& Harford, T.C. (1990). The relationship between ethanol intake and DSM-III-R alcohol dependence. Journal of Studies on Alcohol, 51, 448-456.

Heather, N. (1992). Addictive disorders are essentially motivational problems. British Journal of Addiction, 87, 828-830.

Hunt, W.A., Barnett, L.W. \& Branch, L.G. (1971). Relapse rates in addiction programs. Journal of Clinical Psychology, 27, 455456.

Kalina, E. (1997). Drogadição: Projeto de morte versus projeto de vida. Cura: Transformar esse projeto de morte num projeto de vida. Em N. Fichtner (Org.), Transtornos mentais da infância e da adolescência (pp. 86-91). Porto Alegre: Artes Médicas.

Kalina, E. (1999). Drogadição hoje: Indivíduo, família e sociedade. Porto Alegre: Artes Médicas.

Keen, E. (1979). Introdução à psicologia fenomenológica (H. B. C. Rodrigues, Trad.). Rio de Janeiro: Interamericana.

Kranzler, H.R., Amin, H., Modesto-Lowe, V. \& Oncken, C. (1999). Pharmacologic treatments for drug and alcohol dependence. Psychiatric Clinics of North America, 22, 401-412.

Lanigan, R. (1997). Capta versus data: Método e evidência em comunicologia (C.H. Kristensen, Trad.). Psicologia: Reflexão e Crítica, 10, 17-45.

Leite, J.C. \& Gomes, W.B. (1998). Concepções de alcoolismo e a reabilitação do alcoolista. Em W.B. Gomes (Org.), Fenomenologia e pesquisa em psicologia ( pp. 45-66). Porto Alegre: Ed. Universidade/UFGRS.

Litten, R.Z. \& Allen, J.P. (1998). Advances in development of medications for alcoholism treatment. Psychopharmacology, 139, 20-33.

Maddox, J.F. \& Desmond, D.P. (1981). Careers of opioid users. New York: Praeger.

Marlatt, G.A. (1993). Determinantes situacionais da recaída e intervenções de treinamento de habilidades. Em G.A. Marlatt \& J.R. Gordon (Orgs.), Prevenção de recaída: Estratégias de manutenção de comportamentos aditivos (D. Batista, Trad.) (pp. 64-113). Porto Alegre: Artes Médicas.

Marlatt, G.A. \& George, W.H. (1984). Relapse prevention: Introduction and overview of the model. British Journal of Addiction, 79, 261-273.

Morse, J.M. (1994). Designing founded qualitative research. Em N.K. Denzin \& Y. Lincoln (Orgs.), Handbook of qualitative research (pp. 220-235). Thousand Oaks, California: Sage.

Oliveira, J.A. (1991). A fase adolescente e as motivações para a droga. Em R. Bucher (Org.), Prevenção ao uso indevido de drogas (pp. 63-74). Brasília: Editora Universidade de Brasília.
Pechansky, F., Soibelman, M. \& Jacques, S.M.C. (1994). Estimativas para a severidade da dependência do álcool e possibilidade de melhora: Discordância entre pacientes e psiquiatras. Revista de Psiquiatria do Rio Grande do Sul, 16, 196-201.

Prochaska, J. \& DiClemente, C. (1986). Toward a comprehensive model of change. Em W. Miller e N. Heather (Orgs.) Treating addictive behaviors (pp. 3-27). New York: Plenum.

Ramos, S.P. (1997). Prevenção, diagnóstico, abordagem e tratamento do envolvimento do adolescente com as drogas. Em N. Fichtner (Org.), Transtornos mentais da infância e da adolescência (pp. 279-290). Porto Alegre: Artes Médicas.

Robson, C. (1993). Real World Research. Blackwell: Oxford.

Rosenow, D.J., Niaura, R.S., Childress, A.R., Abrams, D.B. \& Monti, P.M. (1991). Cue reactivity in addictive behaviours: Theoretical and treatment implications. International Journal of the Addictions, 25, 957-993.

Salgueiro, I.J.S. (1995). Âncoras de recuperação no período de póstratamento [Resumo]. Em ABEAD (Org.) Anais do XI Congresso Brasileiro de Alcoolismo e Outras Dependências (p. 137). Belo Horizonte: ABEAD.

Sanchez-Craig, M., Neumann, B.G., Formigoni, M.L.O.S. \& Rieck, L. (1991). Brief treatment for alcohol dependence: Level of dependence and treatment outcome. Alcohol and Alcoholism Suppl, 1, 515-518.

Sannibale, C. (1990). A prospecttive study of treatment outcome with a group of male problem drinkers. Journal of Studies on Alcohol, 50, 236-243.

Schuckit, M.A., Zisook, S. \& Mortola, J. (1985). Clinical implications of DSM-III diagnosis of alcohol abuse and alcohol dependence. American Journal of Psychiatry, 142, 1403-1408.

Scivoleto, S., Henriques, S.G.J. \& Ferreira, I.B. (1995). Adolescentes usuários de drogas/álcool que procuram tratamento: perfil de consumo e fatores preditivos de prognóstico - resultados iniciais. Em ABEAD (Orgs.), Anais do XI Congresso Brasileiro de Alcoolismo e Outras Dependências (p. 107). Belo Horizonte: ABEAD.

Silva, E.A., Ferri, C.P. \& Formigoni, M.L.O.S. (1995). Situações de recaída em pacientes dependentes de álcool e outras drogas durante o tratamento: Um estudo preliminar. Jornal Brasileiro de Psiquiatria, 44, 311-315.

Vaillant, G.E. (1988). What can long-term follow-up teach us about relapse and prevention of relapse in addiction? British Journal of Addiction, 83, 1147-1157.

Vaillant, G.E. (1997). As adições ao longo da vida: Implicações Terapêuticas. Em G. Edwards \& C. Dare (Orgs.), Psicoterapia e tratamento de adições (M.A.V. Veronese) (pp. 05-18). Porto Alegre: Artes Médicas.

Waisberg, J. \& Porter, J. (1994). Purpose of life and outctome of treatment for alcohol dependence. British Journal of Clinical Psychology, 33, 49-64.

Recebido em 13.11.2000

Primeira decisão editorial em 04.03.2002

Versão final em 07.05.2002

Aceito em 14.05.2002 